\title{
Using a Linguistic Theory of Humour in Teaching English Grammar
}

\author{
Rufaidah Kamal Abdulmajeed ${ }^{1}$ \& Sarab Khalil Hameed ${ }^{2}$ \\ ${ }^{1}$ English Language Dept., College of Education for Women, University of Baghdad, Iraq \\ ${ }^{2}$ English Language Dept., College of Arts, University of Baghdad, Iraq \\ Correspondence: Rufaidah Kamal Abdulmajeed. College of Education for Women, University of Baghdad. \\ Baghdad. Al-Jadiriyah Compound. Iraq. E-mail: hajeya2@gmail.com
}

Received: December 10, 2016 Accepted: January 3, 2017 Online Published: January 6, 2017

doi: 10.5539/elt.v10n2p40 URL: http://dx.doi.org/10.5539/elt.v10n2p40

\begin{abstract}
Teachers who teach a new language grammar do not usually have the time and the proper situation to introduce humour when starting a new topic in grammar. There are many different opinions about teaching grammar. Many teachers seem to believe in the importance of grammar lessons devoted to a study of language rules and practical exercises. Other teachers feel that grammar is best learned by doing different language activities without focusing directly on the rules. This paper is devoted to explore the application of the linguistic theory of humour in teaching English grammar. The purpose of the experiment in this study was to show that the humorous way helped the students to learn grammar more effectively and that humour enhanced learning and helped retention and recalling grammar rules. The researchers created a control group and an experimental group to investigate the potential benefits of introducing humour in explaining a new topic of English grammar. The results showed that the exposure to humorous activities in the classroom tend to improve the student's comprehension of the most difficult topics in their grammar book.
\end{abstract}

Keywords: English Linguistics, language learning, grammar, humour

\section{Introduction}

In teaching English grammar to the foreign language learners one must aim at making them efficient users of the language. The learners should be enabled to use the language for all their needs of communications. Some may argue that there is no correlation between teaching grammar and the development of the student's skills in writing and speaking English. They are of the opinion that a language is learnt not by learning its rules but by actually practicing it. In other words, though doing grammar exercises can be a helpful way to learn those grammar rules, many think that immersing themselves in the language allows them to obtain the skills needed without doing intense study. For many others, an approach that incorporates parts of both of the above two methods is most effective because most people who are actively learning English grammar are those who speak other languages.

Grammar is one of those issues that do not have an easy solution. It is tricky and it is tough. Teaching English grammar to a group of students is a a formidable job that requires outstanding skills and superlative efforts to make it successful.

This research raises the following question: does the use of humour in the classroom promote and facilitate the teaching and learning of English grammar?

The researchers have found out that the method which works best, along with all the previous mentioned approaches, is applying the linguistic theory of humour in teaching grammar. It all depends on the teacher's innovative means of teaching.

In this paper, the researchers concentrate on the most problematic subject in English grammar that almost all the students suffer from. It is the "inherent" and "non-inherent" adjectives. This subject is part of their grammar syllabus in the grammar book "A University Grammar of English" by Randolph Quirk and Sidney Greenbaum, 1973.

They carry on an experiment in the classroom. This experiment is planned to discuss this subject in a humorous and non-humorous ways on two groups; control and experimental. The findings of the experiment show that the exam results of the students of the first group, i.e. control group, are not promising while the exam results of the 
students of the second group, i.e. experimental group, who received the subject in a humorous way, are far better than the results of the first group who received the subject in a non-humorous way.

This means that this approach, i.e., using humour, is beneficial in order to improve the students' ability to understand this difficult part of their grammar book. It stands as a solution to this problematic subject in the grammar. The systematic and spontaneous use of humour can help students with this "dull" subject, as they always describe it. The experiment shows that the use of humour helps to change the students' attitude and make them love their course and their teacher as well.

\section{Issues about How to Teach Grammar}

"Let school masters puzzle their brain

with grammar and nonsense and learning;

Good liquor, I stoutly maintain,

Gives genius a better discerning".

"Thus sings Tony Lumpkin in She Stoops to Conquer, reflecting the popular view that grammar is one of the most boring and obscure subjects in the school curriculum. It is perhaps not surprising that grammar should have acquired a reputation for dullness, since very often the way it is taught in the schools seems deliberately designed to kill all interest in the subject." (Allen \& Corder, 1975: 45)

Grammar is an aspect of language about which learners have different opinions. Some learners are very interested in learning grammar rules and doing lots of grammar exercises. Others hate grammar and think it is the most boring part of learning a new language. Whatever opinion one may have, however, one cannot escape from grammar; it is in every sentence you read or write, speak or hear. Grammar is simply the word for the rules that people follow when they use a language; without rules, we would not be able to communicate with other people (How to learn grammar: online)

Therefore, we cannot escape from grammar, but the key question here is; what is the best way to learn grammar? We can learn the rules of a game by simply playing the game. We will certainly make mistakes; we may even get hurt. Eventually, however, we will know how to play. Of course, the rules of a language are very much more complicated than the rules of any game.

We all keep in our minds dull memories from the school days where we had to memorize rules of grammar from old-fashioned handbooks while ignoring the living language that we could hear from audio-visual materials to back up the knowledge we gained from grammar books.

There are too many methods of teaching grammar. The traditional method: "sit down, open your grammar books, turn to page 134, listen to me drone on for 15 minutes...and then do pages 135 , questions one through sixty." This traditional method of teaching grammar is still very popular among experienced teachers and teachers that have been in the profession for a while. However, these traditional teachers have come to realize that there is a fundamental conflict between the traditional grammar they have been accustomed to and the new linguistics, which is being urged upon them (Allen \& Corder, 1975: 54). But it is believed that there is basically no conflict between traditional grammar and modern linguistics. Whereas the traditional handbooks provide descriptions of surface structure, the contemporary linguists discuss theoretical issues and present only as much of the data as is necessary to support the hypotheses (ibid.: 47).

Brown (2007: 423) discusses some issues about how to teach grammar. These issues are:

\section{1) Should grammar be presented inductively or deductively?}

Brown (ibid.) wonders whether the learners benefit from an inductive approach where "various language forms are practiced but in which learners are left to discover or induce rules and generalizations on their own" or whether grammar should be presented in a deductive way by giving learners "rule/generalization by the teacher or textbook and then allowing them to practice various instances of language to which the rule applies" (ibid.).

\section{2) Should we use grammatical explanations and technical terminology in the classroom?}

Brown (ibid.: 424) refers to the importance of the careful use of grammatical explanation and terminology. Teachers should be careful in using metaliguistic knowledge and should not forget the fact that students are busy learning the language itself.

\section{3) Should grammar be taught in separate "grammar only" classes?}

Grammar should be part of the total curriculum so that students can relate grammar to other works in English. It 
is contextualized in meaningful language use (ibid.).

\section{4) Should teachers correct grammatical errors?}

Many students' errors are grammatical. Evidence shows that "rarely is overt grammatical correction by teachers in the classroom of any consequences in improving learners' language." Therefore, it is useful for the teacher to "adhere to principles of maintaining communicative flow, of maximizing student self-correction, and of sensitively considering the affective and linguistic place the learner is in" (ibid.: 426).

In case of teaching an EFL in non-English-speaking country, as in our classes, where the students all speak the same native language, the teacher may benefit from "occasionally using their native language to explain simple grammatical points" (ibid.: 124).

The classes should not be saturated with English language about language, but should contain intervals in the native language of the students. The skillful teachers should manipulate these times to make jocular actions and funny comparison between English and the students' native language to explicate difficult topics in English grammar.

English grammar teachers should be fully aware of the "group dynamics" of a classroom (Dörnyei and Murphy, 2003: 98). It is how the students relate to each other, communicate and cooperate with each other effectively and the effectiveness of the classroom environment (ibid.).

The teacher's role in teaching, just like the parents' role, is supposed to take many guises. Rebecca et al. ((1998) cited in Brown, (2007: 214) says that the teachers' roles are "often described in the form of metaphor: teacher as manufacturer, teacher as doctor, teacher as judge, teacher as gardener, and others." Others may include teachers as joke tellers or people with a sense of humour. These two or more roles are primarily needed within the scope of the subject of the grammar that is discussed in the classroom to make dull grammar rules easily and smoothly perceived, of course, under the teacher's control. These roles should be performed carefully and orchestrally by the teachers. Otherwise they will be aimless and purposeless and may create chaos in the classroom. The way to use humour effectively is the main aim of this paper.

\section{What is humour?}

Humour has a high profile in the society and it is influential as a way of establishing friendships. It is evident that humour refers to anything that people say or do and is perceived as funny and tends to make others laugh.

Humour is defined by Mindess (1971:21) as "a frame of mind, a manner of perceiving and experiencing life. It is a kind of outlook, a peculiar point of view, and one which has great therapeutic power." Ruskin (1985: 1) describes it in the following words: "Somebody hears or sees something and laughs. In most cases, this means that the person finds the audial or visual stimulus funny. Funny situations, funny stories, even funny thoughts occur everyday to virtually everybody."

More and more authors comment on the importance of humour in everyday life and believe that it is an effective way of establishing social connections with others. Morreall (1991: 359) says that people feel more comfortable with the ideas of others when these are presented with humour. A comical speech calms the audience and "enables divergent thinking and effective teamwork all through an extended 'mental flexibility'," as "humor gives temporary legitimation to thinking in impractical and illogical ways" (Ziv, 1983: 69).

Ross (2005: 1) defines humour as "something that makes a person laugh or smile." Ross (ibid.) further emphasizes the strong social aspect of the way people respond to humour. She says that people laugh in company. They do not laugh when they are alone even on the same example that makes them laugh in a room full of people and the same joke can work in one context and die in another.

The social context is important for the creation and reception of humour. It is hard to cross boundaries of time and social group. Humour becomes outdated as fashion does and it is related to particular cultures. There is a time and a place for humour. Sometimes, it is inappropriate in certain situations and in certain times. The social and physical restrictions which are present at a given time and in a given area are totally different from those restrictions which are present at other times and in other areas. Thus, special expressions of humour that might originate within a certain area can be considered as culture specific for a certain length of time. This explains "why the humour of the last decade might no longer be appreciated today and why the humour of a civilization different from ours as a rule does not seem "humorous"” (Rosenthal, 2011).

Humour researchers have found that humour has many benefits for individuals and groups. These findings have been applied to many fields such as medicine, business and education.

Defenders of humour in the classroom say that when handled properly, humour does not encourage chaos in the 
classroom. Although some humour is inappropriate in the classroom such as teasing, racist and sexist humour, yet there is no reason to repress all kinds of humour and then lose its various benefits.

\section{Studies Connecting Humour with Learning}

Many previous studies have highlighted the effects of humour on learning and the relationship between humour and learning. Some agree that there is evidence that the effective use of humour can improve learning but they are still somehow conservative on some points. One of these points is how to use instructional humour effectively. Bryant and Zillmann (1989: 74), for example, say that using instructional humour "depends on employing the right type of humor, under the proper conditions, at the right time, and with proper motivated and receptive students."

The Humour movement has been embraced by teachers and trainers and numerous books are strictly devoted to humour in education recommending the use of humour in the classroom. These books show how humour can "catch and hold students' attention, increase retention of learned material, relieve stress, build rapport between teacher and students, build team spirit among classmates, smooth potentially rough interactions, promote risk taking, and get shy and slow students involved in activities" (Morreall, 2008: 465).

Instructional humour has an appropriate and effective means of increasing the teachers' evaluation and creating a positive classroom environment. "Many would argue that the most important reason is to enhance learning" (Wanzer et al., 2010). This echoes Robinson's (1983: 121) argument that what is "learned with laughter is learned well." Better comprehension and recall of curriculum content is also evident when humour is applied correctly in the classroom (Garner, 2006: 179).

Before heading into exhibiting the connection between humour and learning, let's share this story:

Wanzer (online) starts her research with a story which happened to a friend while she was in the college. Her father asked her why her grades were so poor. She answered him that among other things, her attendance was not always perfect. Before he continued asking her about the problems that prevented her from attending classes regularly, she quickly explained that many of her professors were boring and did not have a sense of humour. Her father answered: "professors are not supposed to be funny."

This story represents the dominant thought that teachers should not be funny in the classroom because this behaviour will underestimate them and make their classes chaotic. Traditional teachers usually suppress humour in the classroom from the first grade to university. They are not comfortable with the humour in the classroom. They criticize it because they think it causes disrespect of the authority of the teachers.

This attitude towards humour has been overturned by many primary and secondary school teachers nowadays. Recent Studies indicate that students overwhelmingly prefer professors who use humour in their instruction and interaction with students to those who do not.

The pedagogical use of humour has psychological and physiological effects on learners. The psychological effects of humor and laughter, on one hand, "have been shown to reduce anxiety, decrease stress, enhance self-esteem and increase self-motivation," while the physiological effects of humor and laughter, on the other hand, "can aid learning through improved respiration and circulation, lower pulse and blood pressure, exercise of the chest muscles, greater oxygenation of blood, and the release of endorphins into the bloodstream." (Garner, 2006: 177).

In this respect, Kaplan and Pascoe (1977: 65) argue that "humour need to be relevant to the instructional material to increase learning." This finding comes from an experiment conducted by them on college students who receive a lecture with relevant humour and a lecture without humour. The results indicate that humour helps students and improves their level of learning the lecture material. They conclude by saying that "the use of humor significantly increases recall for only those items based on humorous examples" (ibid.).

Cornett (1986: 8) adds that humour for educators is the "most powerful resource to achieve a wide range of beneficial educational outcomes." He thinks that humorous instruction is beneficial among researchers who concentrate on the positive consequences of classroom humour and how this humour results in an increased motivation and learning.

But what are the specific benefits of using humour in the classroom? Cornett (ibid.) gives examples of the outcomes of humour in education such as "controlling problematic behavior and facilitating foreign language acquisition," whereas Teslow (1995: 9) concentrates on the classroom environment. He says that "humour has long been recognized as a beneficial strategy in education as a tension reliever." In other words, humour is used as a tool for relieving tension and is useful in teaching topics that are generally considered by students as a 
source of anxiety.

Prosser's (1997: 698) experiment validates this hypothesis. He makes a questionnaire distributed among 210 higher education teachers in order to collect opinions about the use of humour in adult education. The results show that $99 \%$ of the participants consider humour as an important tool in teaching, and $79 \%$ "regularly welcomed spontaneous humour" (ibid.). Prosser considers spontaneous humour as the most successful type of humour for teaching adults because it is effective in engaging the students in the classroom.

Many teachers now "agree on the central benefits of humour in the classroom. It makes the teacher appear fully human that relaxes the students, creates an open and non-threatening atmosphere for learning, gets and holds attention, increases retention of learned material, promotes critical thinking, and promotes divergent or creative thinking" (Morreall, 2008: 472). It is used as a tool to improve the language development of students with special educational needs and it can predict gifted students' aptitude for language because it functions as an effective indicator of advanced linguistic understanding (Morrison, 2008, cited in Boyle (2014: 288).

Moreover, humour has several functions. It can be influential in many positive ways and has a variety of positive functions such as increasing group cohesion, coping with stress and creating an enjoyable environment (Banas et al., 2011).

Instructional humour plays an important role in facilitating learning but its effectiveness depends on the students' ability to perceive and then resolve the incongruity in a humorous instruction. If they do not resolve the incongruity, they may not recognize and do not receive the message correctly. In this case confusion will replace humorous message.

This means that the recognition of humour will increase the students' attention and their recalling and learning if two important considerations are recognized: the relevance and the appropriateness of humour. First, relevance means the relationship between humour and the course content which may increase the students' motivation and their ability to comprehend the contents; second, the appropriateness of humour influences the effective response of the students and, as Banas et al. (2011) see it, "appropriate forms of humour create positive affect while inappropriate forms create negative affect."

Using humour in the classroom is a skill that must be acquired by an expert and a professional teacher. Teachers with long teaching experience tend to be more humorous than those who have less experience because they know how to use and relate humour to the course significantly and effectively. It is a matter of personality traits. High-humour oriented teachers have more developed schema of humour as well as a wider repertoire of humorous behaviour (Martin, 2007 cited in Banas et al., 2011).

Therefore, using competent instructional humour in learning is complex. Instructional humour in the classroom is not a simple matter. It depends on a number of factors. Consequently researchers have taken different approaches in their research about humour in the classroom. One of these factors, as Teslow (1995: 8) puts it, lies the fact that "styles of humour are culture-dependent." Different cultures have different sources of humour and humour is perceived differently in these cultures, so what is considered funny in a certain place is not necessarily funny in another. In other words, this factor must be taken into consideration in order to ensure the efficacy of instructional humour in the classroom.

\section{The Experiment}

The researchers created a group of (38) students, from the second year of the Department of English, College of Education for Women, University of Baghdad, to be the sample of their experiment. The students are divided into a control group and an experimental group. These students suffer from the difficulty of understanding the most problematic subject, namely; 'inherent' and 'non-inherent' adjectives, a subject in the grammar book entitled "A University Grammar of English" by Quirk et al. They have never heard of these types of adjectives. The researchers feel that this subject is rather difficult for these learners of English as a second language and they made many attempts to make it easy for them. They tried too many ways to make those students learn the lessons but the results were not promising. At the end, the agreement was made to try teaching it in a humorous way.

The experimental group consists of (19) students with whom the researchers worked in applying the linguistic devices of humour: metaphor, pun, and ambiguity. These devices are used in explaining the subject as well as engaging the students in some humorous, funny and incongruous activities which evoke laughter.

Examples of these activities are:

1) The researchers (teachers) chose a number of students and gave each one a new name. They became Misses 
inherent and Misses non-inherent adjectives, and were asked to pin their new names on their shirts. Then the teachers took part in acting sentences with these types of adjectives. The teacher's role in this activity was like the director of a play and the students were made to take part in the acting.

Misses inherent adjectives retain the same meaning whether when they modify nouns (other students are named Nouns) or not when they stand alone in the predication. Wherever the nouns stand in the class, those inherent Misses follow them to show that they retain the same meaning, while Misses non-inherent adjectives do not follow the nouns and they retain the same meaning when they move away from the nouns.

2) The teachers brought coloured portraits, photos, and even pictures of nature and asked the students to write short paragraphs on these photos and to use their imagination to write short stories explaining the content of these photos and using this kind of adjectives. They composed wonderful stories in their own words describing the scenes and the figures in these photos and using metaphor, pun and ambiguous words and sentences to evoke laughter. It was a kind of student-centered classroom.

The control group, on the other hand, also consists of (19) students. They received the subject by a more traditional and conventional method of teaching. The teacher was serious and dealt with students in a very formal and conventional way. She wrote the rule on the board and then made some exercises from their drill books. The students did their job in a very conventional way by "sit down, get out your grammar books" method; the traditional method of teaching grammar. The class was some sort of teacher-centered class.

At the end of each lesson, a quick quiz was made for the students in both groups at the same time and with the same questions and same length of time. The quiz contained one question: What are inherent and non-inherent adjectives? Explain with examples.

\section{Results and Discussion}

The results showed that the grades of students in the control group were much lower than the grades of the experimental group, as the following chart shows:

\begin{tabular}{lllllllll}
\hline $\begin{array}{l}\text { Control Group } \\
\text { (19) students }\end{array}$ & \multicolumn{7}{c}{$\begin{array}{l}\text { Experimental Group } \\
\text { (19) students }\end{array}$} \\
\hline $\begin{array}{l}\text { Students with } \\
\text { answers }\end{array}$ & correct & $\begin{array}{l}\text { Students } \\
\text { answers }\end{array}$ & with & incorrect & $\begin{array}{l}\text { Students with correct } \\
\text { answers }\end{array}$ & $\begin{array}{l}\text { Students } \\
\text { answers }\end{array}$ & with incorrect \\
5 & 14 & 13 & & 6 & \\
\hline
\end{tabular}

The results showed that the number of students who did well in the experimental group is significantly higher than the students with correct answers in the control group.

This indicates that creating an atmosphere of familiarity and fun gives positive results. Getting rid of fear and boredom in the classroom would accelerate the learning process, and the consolidation of information proves the workability of the experiment.

This experiment has changed the mood of the students, made them happy with what they are doing in the classroom and encouraged them to speak with each other to eliminate the hesitation they feel when speaking the language orally. Besides, they seemed to have much fun by laughing at each other's mistakes while practicing the language thus breaking the dullness of the lesson.

This method is very much dependent on the teacher's creativity and his/her ability to weave grammar into every other area of the English classroom. It is by no means the easiest way to teach grammar, but as the research has shown, it may be the most effective. It is definitely the method that takes the most time and creativity on the part of the teacher.

\section{Conclusion}

The use of humorous methods to create an atmosphere of fun, humour and laughter is considered a break from the rigidity of the old methods. Traditional instruction, based on automated rote learning, creates a sense of boredom, dulls the students' appetite for learning, and hinders retension of information and development of learning skills. Besides, these humorous methods bring the students closer to their teachers, make them happier in the classroom and more open to learning, thus creating a healthy environment where teachers and students cooperate and participate in the learning process. 
Many experts, educators and researchers seem to believe in the infinite possibilities of the human potential. For this reason, they keeep searching for mechanisms to help the students improve their ability to learn and absorb information in a positive way and to develop the capacity and skills that qualify him/her for success in all fields of scientific and practical learning. Our experiment of the use of humour in the classroom is one of these new methods of education. The results of the experiment explained above show that humour can reduce anxiety, help relieve stress, increase mental sharpness and help students to learn difficult English grammatical subjects.

\section{References}

Allen, J. P. B., \& Corder, S. P. (1975). Papers in Applied Linguistics. London: Oxford University Press. The Edinburgh Course in Applied Linguistics.

Banas, J. A., Norah, D., Dariela, R., \& Shr-Jie, L. (2011). A Review of Humor in Educational Settings: Four Decades of Research Communication Education. National Communication Association, 60, 115-144.

Boyle, F., \& Niamh, S. (2014). An Exploration Study into the Possible Benefits of Using Humor in Creative Tasks with a Class of Primary Five Pupils. HUMOR: International Journal of Humor Research, 27(2), 287-306. https://doi.org/10.1515/humor-2014-0029

Brown, H. D. (2007). Teaching by Principles: An Interactive Approach to language Pedagogy (3rd ed.) New York: Pearson Education, Inc. Longman.

Bryant, J., \& Zillmann, D. (1989). Using Humor to Promote Learning in the Classroom. In P. E. McGhee (Ed.), Humor and children's development: A guide to practical applications (pp. 49-78). New York: Haworth Press.

Cornett, C. E. (1986). Learning through laughter: Humor in the classroom. Bloomington, In Phi Delta Kappa Educational Foundation.

Dörnyei, Z., \& Murphy, T. (2003). Group Dynamics in the Language Classroom. Cambridge: Cambridge University Press. https://doi.org/10.1017/CBO9780511667138

Fry, William F. Jr. (1963) Sweet Madness. Palo Alto, Ca: Pacific Books. https://doi.org/10.1037/11790-000

Garner, R. L. (2006). Humor in pedagogy: How ha-ha can lead to aha! College Teaching, 54(1), 177-180. https://doi.org/10.3200/CTCH.54.1.177-180

How to learn Grammar. A Guide to Learning English. Retrieved September, 20, 2015 from http://esl.fis.edu/learners/advice/gram.htm

Kaplan, R. M., \& Pascoe, G. C. (1977). Humorous lectures and humorous examples: Some effects upon comprehension and retention. Journal of Educational Psychology, 69, 61-65. https://doi.org/10.1037/0022-0663.69.1.61

Mindess, H. (1971). Laughter and Liberation. Los Angeles: Nash.

Morreall, J. (1991). Humor and Work. Humor: International Journal of Humor Research, 4(3-4), 359-373. https://doi.org/10.1515/humr.1991.4.3-4.359

Morreall, J. (2008). Applications of Humor: Health, the workplace, and education. In V. Raskin, \& W. Ruch (Eds.), The Primer of Humor Research. New York: Mouton de Gruyter. https://doi.org/10.1515/9783110198492.449

Prosser, B. R. (1997). The Use of Humor Among Adult Educators in a Formal Classroom Setting. Dissertation Abstracts International, Section A: Humanities and Social Sciences, 58(3-A).

Quirk, R., Sidney, G., Geoffrey, L., \& Jan, S. (1973). A University Grammar of English. Essex: Longman Group UK Limited.

Rajalakshmi, K. (2015). Effective Ways to Teach English grammar. Retrieved September, 15, 2015 from www.teachingenglish.org.uk

Raskin, V. (1985). Semantic Mechanisms of Humor. Dordrecht-Boston-Lancaster: D. Reidel. https://doi.org/10.1007/978-94-009-6472-3_2

Robinson, V. M. (1983). Humor and health. In P. E. McGhee, \& J. H. Goldstein (Eds.), Handbook of Humor Research (Vol. II, pp. 109-128). New York: Springer-Verlag. https://doi.org/10.1007/978-1-4613-8236-2_7

Rosenthal, F. (2011). Humour in Early Islam with an introduction by Geert Jan van Gelder. Leiden. Boston: Brill. (Brill Classics in Islam). 
Ross, A. (2005). The Language of Humour. London: Routledge. https://doi.org/10.1021/la0504098

Teslow, J. L. (1995). Humor me: A call for research. Educational Technology Research and Development, 43, 6-28. https://doi.org/10.1007/BF02300453

Wanzer, M. (2015). Use of Humor in the Classroom: The Good, the Bad, and the Not-So-Funny Things That Teachers Say and Do.

Wanzer, M. B., Frymier, A. B., \& Irwin, J. (2010). An explanation of the relationship between instruction humor and student learning: Instructional humor processing theory. Communication Education, 59, 1-18. https://doi.org/10.1080/03634520903367238

Ziv, A. (1983). The Influence of Humorous Atmosphere on Divergent Thinking. Contemporary Educational Psychology, 8(1), 68-75. https://doi.org/10.1016/0361-476X(83)90035-8

\section{Copyrights}

Copyright for this article is retained by the author(s), with first publication rights granted to the journal.

This is an open-access article distributed under the terms and conditions of the Creative Commons Attribution license (http://creativecommons.org/licenses/by/4.0/). 